\title{
AFTERSHOCK GAME: Bermain dan Belajar Mitigasi Gempa Bumi dengan Cara yang Menyenangkan
}

\author{
Titi Pambudi Karuniawaty", Adnanto Wiweko, Ajeng Hardanti, Intan Karmila, \\ Nurul Imaniaty As-Syarifiah \\ Faculty of Medicine, University of Mataram, Mataram, Indonesia
}

\author{
Article history \\ Received: 15 Desember 2019 \\ Revised: 20 Januari 2020 \\ Accepted: 19 Maret 2020 \\ *Corresponding Author: \\ Titi Pambudi Karuniawaty \\ Faculty of Medicine, University \\ of Mataram, Mataram, \\ Indonesi $a$; \\ Email: \\ tp_karuniawaty@unram.ac.id
}

Abstract: Indonesia's position in the ring of fire and the great earthquake experience on Lombok Island a while ago led to the education and mitigation of earthquakes is very important. These two things should be introduced early on and carried out continuously. The mitigation of earthquakes in school-age children will be more effective through a fun game as learning activity as well as educational tools. Aftershock Game is a non-digital card game specially designed to teach players to take attitudes quickly and precisely in the event of an earthquake. Playing activities while learning by using Aftershock Game has been conducted at MI Tazhib Kekait, one of the earthquakes affected locations. 90 elementary school children on $3^{\text {rd }}-5^{\text {th }}$ grade played this game as disaster mitigation education. This game was conducted in 15 small groups of 4-6 people. Activities are accompanied by a facilitator for 15-20 minutes per group, then at the end of each game students are required to give feedback on the Aftershock game. The performance of the game's aspect assessment shows that Aftershock Game is easy to play, fun and has high replay ability with a mean score of 8.89 out of a maximum score of 10 . The game's design aspect also shows good value (mean score 8.32). Repairs are required on illustration and packaging boxes to be more durable when used. Educational materials on the earthquake and the mitigations are well delivered, with comprehensive content (mean score 8.82). Aftershock Game is an earthquake education game that is easy to play, interesting and comprehensive. This game is suitable for school aged children and can be developed as a community educational tools regarding the mitigation of earthquakes.

Keywords: aftershock-game; children; education; illustration

Abtrak: Posisi Indonesia yang berada di cincin api dan pengalaman gempa besar di Pulau Lombok beberapa waktu yang lalu menyebabkan edukasi dan mitigasi gempa bumi sangatlah penting. Kedua hal ini harus dikenalkan sejak dini dan dilakukan secara kontinyu. Pengenalan gempa bumi dan mitigasinya pada anak usia sekolah akan lebih efektif jika dilakukan dengan cara menyenangkan melalui permainan sebagai aktivitas belajar sekaligus media edukasi. Aftershock Game merupakan permainan kartu non digital yang dirancang khusus untuk mengajarkan pemainnya mengambil sikap secara cepat dan tepat saat terjadi gempa bumi. Kegiatan bermain sambil belajar menggunakan Aftershock Game telah dilakukan terhadap 90 anak sekolah dasar kelas 3, 4 dan 5 di MI At Tazhib Kekait, yang merupakan salah satu lokasi terdampak gempa. Edukasi mitigasi bencana melalui permainan dilakukan pada 15 kelompok kecil yang terdiri dari 4-6 orang. Kegiatan berlangsung dangan didampingi fasilitator selama 15-20 menit per kelompok, kemudain di akhir permainan setiap siswa diminta memberikan umpan balik terhadap Aftershock game. Penilaian aspek game performance menunjukkan 
bahwa Aftershock Game mudah dimainkan, menyenangkan dan memiliki replayability tinggi dengan rerata skor 8.89 dari total skor maksimal 10. Aspek desain permainan juga menunjukkan nilai cukup bagus (rerata skor 8.32). Perbaikan diperlukan pada gambar ilustrasi dan kemasan box agar lebih awet saat digunakan. Materi edukasi tentang gempa dan mitigasinya tersampaikan dengan baik, dengan isi konten yang cukup komprehensif (rerata skor 8.82). Aftershock Game merupakan permainan edukasi gempa bumi yang mudah dimainkan, menarik dan materinya komprehensif, serta cocok untuk anak usia sekolah dan dapat dikembangkan sebagai media edukasi mengenai mitigasi gempa bumi pada masyarakat umum.

Kata Kunci: anak-anak; ilustrasi; edukasi; Game Aftershock

\section{PENDAHULUAN}

Indonesia merupakan negara yang terletak di "The Pacific Ring of Fire" (deretan gunung api pasifik) dan berada di pertemuan empat lempeng tektonik mayor, sehingga Indonesia merupakan wilayah yang rentan terhadap bencana gempa bumi, tsunami dan letusan gunung api (Siagian, 2014). Terdapat beberapa gempa besar dalam tahun 2018 seperti Gempa Lombok dan Sulawesi Tengah, dengan jumlah korban ratusan meninggal dan ribuan luka-luka. Sebagian besar cedera disebabkan oleh kejatuhan bangunan yang roboh. Cedera terbanyak yang terjadi pada saat gempa adalah di bagian kepala, dada dan anggota gerak (Peek-Assa, 1998)

Melihat potensi kefatalan cedera karena gempa dan banyaknya gempa yang terjadi di Indonesia, maka edukasi dan mitigasi bencana gempa bumi penting dilakukan. Kedua hal ini harus diperkenalkan kepada semua kalangan sejak dini dan secara terus menerus. Telah dibuktikan, di negara berkembang terkadang edukasi bencana tidak selalu dapat dilakukan karena kurangnya ahli dan materi edukasi. Oleh karena itu penting untuk mengintregasikan program edukasi ke dalam aktifitas anak-anak (Izadkhah, 2005).

Pengenalan gempa bumi dan mitigasinya pada anak-anak dapat dilakukan dengan cara menyenangkan. Bermain merupakan bentuk aktivitas belajar yang efektif, sehingga media edukasi dan mitigasi lewat permainan sangat tepat. Game Aftershock ini merupakan permainan kartu non digital yang dirancang untuk mengajari pemainnya bersikap saat terjadi dan paska terjadi gempa bumi. Permainan ini dikembangkan dari beberapa buku saku kesiapsiagaan gempa bumi yang diterbitkan BNPB.

Board game atau permainan papan dapat meningkatkan pengetahuan terkait suatu hal, mendorong motivasi belajar dan perilaku positif pada anak (Viggiano et al., 2018). Permainan papan juga melibatkan interaksi dengan pemain lain sehingga mampu melatih keterampilan sosial partisipan (Mostowfi, 2016). Metode ini menjadi salah satu alternatif metode pembelajaran di samping metode konvensional seperti ceramah dan diskusi (Giannakos, 2013). Keunggulan utama permainan papan adalah menyenangkan dan mengandung unsur permainan (Ober, 2016). Permainan yang menyenangkan dapat meningkatkan luaran kognitif dan perilaku yang diharapkan dari permainan tersebut (Giannakos, 2013).

Dua buah buku saku kesiapsiagaan terbitan BNPB tahun 2012 dan terbitan BNPB tahun 2017 menjadi dasar materi Aftershock Game. Poin-poin dalam kedua buku saku yang terkait materi gempa bumi diambil dan dimasukkan sebagai bagian dari permainan. Cara bermain Aftershock Game dikembangkan dengan proses game design yang sesuai dengan alur pembuatan serious game dimana keseimbangan antara materi edukasi dan cara main yang menyenangkan selalu dijaga. 
Kegiatan pengabdian kepada masyarakat, khususnya yang melibatkan anak-anak ini bertujuan untuk memberikan edukasi dan mitigasi gempa bumi kepada masyarakat melalui media permainan. Manfaat yang diharapkan dari kegiatan ini adalah meningkatnya pengetahuan tentang mitigasi gempa bumi dan masukan untuk perbaikan Aftershock Game.

\section{METODE}

Pengembangan Aftershock Game dipublikasikan secara terpisah (dalam proses), namun secara garis besar, peneliti telah merumuskan tujuan permainan, nilai (value) yang diutamakan dalam permainan serta konten pengetahuan yang dimasukkan sejak awal pembuatan Aftershock Game. Dengan alasan kesederhanaan dan validitas materi edukasi, konten game ini diambil dari 2 buah buku saku terbitan BNPB, yaitu buku saku siaga bencana tahun 2012 dan tahun 2017. Desain mekanik dan visual dikerjakan oleh tim peneliti.

Aftershock Game merupakan permainan non digital berbentuk kartu. Cara bermain Aftershock Game terinspirasi dari permainan Wanted dengan mekanisme utama kecepatan tangan. Dalam permainan ini, para pemain diberikan misi untuk bersikap tepat dan cepat dengan memilih tindakan yang benar saat terjadi gempa bumi. Terdapat berbagai skenario gempa bumi dengan 7 pilihan tindakan. Satu skenario memiliki antara 1-3 tindakan yang tepat. Pemain saling mendahului memilih tindakan yang tepat begitu skenario selesai dibacakan. Permainan ini dirancang untuk dimainkan oleh 3 - 6 pemain mulai dari anak-anak usia SD kelas 3 hingga dewasa. Pemenang dalam permainan ini adalah pemain yang mampu menjawab tepat dan cepat tindakan yang benar saat terjadi gempa sehingga paling sedikit kehilangan kartu keselamatan.

Setelah purwarupa pertama dibuat, peneliti melakukan uji coba permainan dan merancang kuesioner umpan balik terhadap permainan. Kuesioner dirancang dengan bahasa yang sederhana agar dapat dipahami oleh pemain anak-anak karena permainan ini dirancang untuk dapat dimainkan oleh anak usia sekoah.

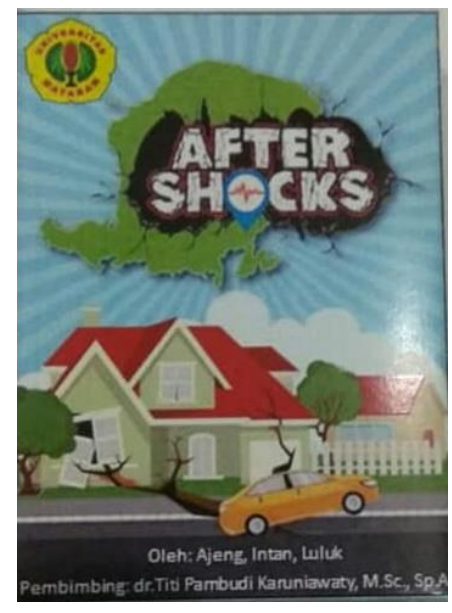

Gambar 1. Aftershock Game 


\section{HASIL DAN PEMBAHASAN}

Kegiatan pengabdian ini telah dilaksanakan pada 19 Juli 2019 di MI At Tazhib Kekait, Gunung Sari , Lombok Barat. Kegiatan penyuluhan dimulai pada pukul 08.00 dan selesai pukul 11.00 WITA. Kegiatan ini merupakan kolaborasi dari FK UNRAM, STIKES Yarsi Mataram, IDI Mataram serta INDOHUN. Juga hadir perwakilan BPBD Lobar dan Puskesmas Gunung Sari. Kegiatan ini ditujukan kepada sebanyak 90 orang siswa kelas III - VI terdiri dari 15 kelompok kecil dengan anggota kelompok 4-6 orang. Masing-masing kelompok bermain Aftershock Game bersama fasilitator, kemudian di akhir permainan pemain diminta untuk mengisi kuesioner terkait tanggapan terhadap cara bermain, gambar/desain dan materi edukasinya.

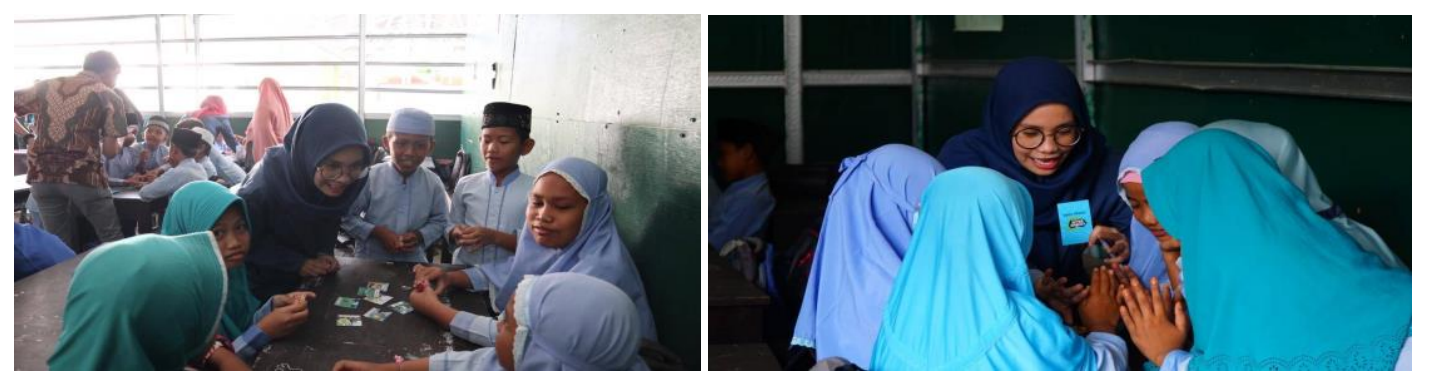

Gambar 2. Suasana permainan penuh kegembiraan di tengah permainan Aftershock Game

Tabel 1. Tanggapan pemain terhadap aspek cara main, gambar dan materi edukasi Aftershock Game

\begin{tabular}{|c|c|c|}
\hline Aspek & Parameter/Pernyataan & Rerata nilai \\
\hline \multirow[t]{4}{*}{ Gameplay } & Card game ini secara umum mudah dimainkan & 8,65 \\
\hline & Aturan bermain card game jelas dan mudah dipahami & 8,75 \\
\hline & Bermain card game ini terasa menyenangkan & 9,45 \\
\hline & Selesai memainkan game ini, muncul keinginan memainkannya lagi & 8,70 \\
\hline \multirow{7}{*}{$\begin{array}{l}\text { Gambar/desain } \\
\text { grafis }\end{array}$} & Secara umum, gambar/design dalam card game ini menarik & 8,55 \\
\hline & Gambar dalam card game ini sesuai untuk semua umur (Family game) & 8,91 \\
\hline & Gambar dalam card game sesuai tema/topik edukasi & 9,08 \\
\hline & Gambar card game sesuai dengan narasi dan alur cerita yang dibangun & 8,5 \\
\hline & Kemasan box baik dan tidak mudah rusak & 7,17 \\
\hline & Ukuran kartu cukup besar dan nyaman digenggam & 8,35 \\
\hline & Desain kartu menarik dan jelas terbaca & 7,67 \\
\hline \multirow[t]{3}{*}{$\begin{array}{l}\text { Cerita dan } \\
\text { materi edukasi }\end{array}$} & $\begin{array}{l}\text { Penggunaan istilah dan susunan kalimat pada game ini mudah } \\
\text { dipahami }\end{array}$ & 8,7 \\
\hline & Materi edukasi dalam card game ini mudah ditangkap dan dipahami & 9,17 \\
\hline & $\begin{array}{l}\text { Pesan/tujuan permainan ini dapat ditangkap/tersampaikan dengan } \\
\text { baik. }\end{array}$ & 8,58 \\
\hline
\end{tabular}

Kuesioner umpan balik terdiri dari 14 pertanyaan yang dibagi dalam 3 bagian yaitu aspek cara main, ilustrasi dan desain grafis serta konten materi edukasi. Secara umum untuk kelompok cara main, Aftershock Game mudah dimainkan, menyenangkan dan memiliki replayability yang bagus. Skor rerata kelompok ini 8.89 dari total skor maksimal 10. Untuk aspek desain nilainya cukup bagus, rerata 8.32. Namun nilai sedikit kurang di kemasan box dan gambar ilustrasi. Aspek cerita dan konten 
nilainya bagus dengan rerata 8.82. Materi edukasi tentang gempa dan mitigasinya tersampaikan dengan baik, dengan isi konten yang cukup komprehensif. Hasil lengkap bisa dilihat pada tabel 1 .

Rerata skor total sebesar 8.58 menunjukkan secara umum Aftershock Game disukai anak anak, memiliki gambar dan desain yang bagus dan konten materi edukasinya mudah dipahami. Namun masih terdapat kekurangan di gambar yang belum orisinal. Namun, karena ini masih prototipe awal gambar dan grafis memang belum dikerjakan dengan melibatkan ilustrator dan tenaga professional. Pada prototipe akhir, ilustrasi dan grafis akan dikerjakan oleh tenaga professional.

Aftershock Game mendapat beberapa masukan dalam hal tulisan pada kartu yang perlu diperbesar agar jelas terbaca, bahan dari kartu sebaiknya tidak mudah rusak, kartu situasi diperbanyak lagi agar waktu bermain lebih lama dan ilustrasi dibuat lebih orisinil.

\section{KESIMPULAN DAN SARAN}

Aftershock Game merupakan permainan edukasi gempa bumi yang mudah dimainkan, menarik dan materinya komprehensif. Permainan ini cocok dimainkan untuk anak usia sekolah dan dapat dikembangkan sebagai media edukasi mengenai mitigasi gempa bumi pada masyarakat umum.

\section{Ucapan Terima Kasih}

Penulis mengucapkan terima kasih kepada Fakultas Kedokteran Universitas Mataram dan IDI Kota Mataram selaku penyelenggara kegiatan, MI At Tazib Kekait sebagai lokasi kegiatan dan INDOHUN sebagai pengundang tim pengabdian masyarakat Aftershock Game. Tim terutama berterimakasih kepada fasilitator dan siswa siswi MI At Tazhib kekait yang terlibat dalam kegiatan ini.

\section{DAFTAR PUSTAKA}

Aguiar, M., Stollenwerk, N., Halstead, S.B. 2016. The Impact of the Newly Licensed Dengue Vaccine in Endemic Countries. PLoS Neglected Tropical Diseases 10(12): 5179. https://doi.org/10.1371/journal.pntd.0005179

Peek-Asa, C., F. Kraus, J., B. Bourque, L., Vimalachandra, D., Yu, J., Abrams, J., 1998. Fatal and hospitalized injuries resulting from the 1994 Northridge earthquake. International Journal of Epidemiology, 27(3). p: 459-465 https://doi.org/10.1093/ije/27.3.459

Giannakos M.N, 2013. Enjoy and learn with educational games: Examining factors affecting learning performance. Computers \& Education. vol. 68. p: $429-439$.

Izadkhah, Y.O., Hosseini, M., 2005. Towards resilient communities in developing countries through education of children for disaster preparedness. International Journal of Emergency Management, 2(3)

Mostowfi, M., Mamaghani, N.K., Khorramar, M. 2016. 'Designing Playful Learning by Using Educational Board Game for Children in the Age Range of 7-12: (A Case Study: Recycling and Waste Seperation Education Board Game), International Journal of Environmental and Science Education, 11(12). p: 5453-5476.

Ober, C. P. 2016. Assessment of Student Engagement When Using a Novel Board Game for Teaching Thoracic Radiography to Fourth-Year Veterinary Students. Medical Science Educator, 26(1). p: 39-42. 